This is a post print version of an article published by SAGE in Time \& Society in 24(1) 2015, pp. 5-26. Available online: DOI: 10.1177/0961463X14523925.

Kirsi Juhila, Kirsi Günther \& Suvi Raitakari

\title{
NEGOTIATING MENTAL HEALTH REHABILITATION PLANS: JOINT FUTURE TALK AND CLASHING TIME TALK IN PROFESSIONAL CLIENT INTERACTION
}

\begin{abstract}
:
This article explores how discourses of time are produced and negotiated in professional client interaction when making mental health rehabilitation plans. The discourse of linear time is dominant in interaction, and shared by both participants to create joint future talk. However, the clients might challenge the dominant time talk by using the discourse of the time of mindful body, resulting in clashing time talk. The discourses of time are linked with identity categorisation, and with the criteria of 'good' and 'bad' professional work and clienthood. The analysis demonstrates the relevancy and consequentiality of time talk in professional client interaction.
\end{abstract}

Key words: planning, change-oriented social work, interaction, discourses of time, identity categorisation 


\section{INTRODUCTION: SOCIAL REHABILITATION, FUTURE ORIENTATION AND PLANS}

The purpose of this article is to explore how the issue of time is present and negotiated in professional client interaction, whose institutional agenda is to produce mental health rehabilitation plans for clients. The mental health rehabilitation being studied is conducted in a supported housing unit, which emphasises social rehabilitation, such as strengthening social capabilities and integration into the community. Accordingly, it can be characterised more as social work than as health care work or medical rehabilitation. Social work relies on certain shared premises of time. One of the basic premises is that social work is change work and hence oriented toward the future. The ideal helping process in social work practice is typically defined as containing the following phases: 1) exploration, assessment and planning, 2) intervention or implementation, 3) goal attainment and termination (e.g. Hepworth et al., 2009). In face-to-face interaction between professionals and clients, the past, present and future of individual clients are continuously talked into being. The problems and troubles at hand are seen as being the consequences of past events and experiences; the present situations are assessed, and future paths are discussed and planned. Social work as social rehabilitation strongly follows the ideal that it is a helping process and thus focuses on the future. The aim of rehabilitation is to increase clients' social well-being. The expectation is that professionals and clients will jointly produce concrete aims for clients' futures and the pathways to achieve them.

In addition to the professional theories of helping processes, change and future orientation is stressed in social and health legislation, in administrative rules and guidelines, and in institutional 
agendas by various helping institutions. According to these legislative and administrative regulations, guidelines and aims, change is not something that just happens, but is understood as being a scrutinised, well planned and client centred process aimed toward the future, where clients' problems have been solved or reduced, and their life management and well-being have increased. Correspondingly, professionals are expected to produce 'future plan' documents for clients in collaboration with them. Plans are often made by using ready-made forms, which professionals fill in and clients check and accept after joint conversations and assessment processes. Depending on institutional contexts, these plans can be named care or activation plans, or as rehabilitation plans as is the case in a supported housing unit. (Günther and Raitakari, 2008.)

\section{TAKEN-FOR-GRANTED AND ALTERNATIVE DISCOURSES OF TIME}

Change work emphasising future orientation is such a taken-for-granted assumption in social work that it can be called as a received idea difficult to criticise or call into question (Rojek et al., 1988). However, Fahlgren (2009: 212) takes a polemic stance towards the dominant way of understanding time in social work:

I read the very idea of social work as something that is change oriented as a notion created within the discourse of linear time. In this discourse the meaning of time is created and naturalized that can be dissected into the past, the present and the future, with the time arrow showing the directions of events unfolding in sequence towards the future.

Leccardi (1999: 5-6) argues that when past, present and future are understood as separate dimensions, the future becomes open to control and planning. This follows the idea what Suchman (1997) calls as a rational planning model relying on rational actions and actors: the 
model 'treats a plan as a sequence of actions designed to accomplish some preconceived end' (Suchman 1997: 28). The rational planning model is thus based on the discourse of linear time. As Davies (1994: 290) puts it: 'one plans activities within a timetable, which then provides the possibility of showing what one has done.'

In social rehabilitation work, which relies on the linear discourse of time, preferable time arrows show upwards and indicate positive changes and directions in clients' future lives, whilst descending or horizontal time arrows symbolise failures or stagnations. The failures and stagnations are crucial in social rehabilitation. If the desired upward change is not seen as happening in a certain period of time, or if the arrow is interpreted as being downhill, this easily creates a sense of unsuccessfulness or even shame among both professionals and clients. Unrealised plans of change might also justify stronger interventions to clients' lives (Fahlgren 2009: 212). The tendency to prefer ascendant time arrows, meaning progressive life pathways presupposing improvement and development within time is widely shared in Western cultures. People are expected to grow towards a greater maturity and responsibility in their life spans from childhood to adulthood (Coupland and Nussbaum, 1993; Taylor and Wetherell, 1999; Holstein and Gubrium, 2000). This cultural dominance of discourse of linear time to which we all have been socialised makes it difficult to approach time alternatively in social work settings (see Adam 1995: 59-83).

Although often taken for granted, linear time is not the only way to understand time. There is a long tradition in social sciences of discussing alternative ways of thinking about the role of temporal phenomena. The work of Adam $(1990 ; 1995)$ is highly influential in the field and important when studying time in human service settings (e.g. Davies, 1994; Fahlgren, 2009). 
Adam (1995) writes about the coexisting of multiple times. The linear discourse of time or clock time as it is also called, conceals and makes it difficult to see and talk about alternative time discourses. In spite of this dominance, social interactions and practices display aspects of multiple times. These alternative discourses have been named in the literature such as cyclic and process times. Cyclic time is based on the rhythms and repetitions of nights and days, seasons etc. thus challenging an idea of a linearly progressing future. Process time relates to the rationality of caring, claiming that there are activities that cannot be fitted to task-oriented linear clock-time. Caring work is based on the here and now (and also daily repetitive) needs of the people being cared for. Taking care of those needs is a process whose duration or content are not possible to know in advance (Davies, 1994: 279-282).

Following Fahlgren (2009), who relies largely on Adam's work, we conceptualise an alternative approach to temporality as the discourse of time of the mindful body, which is close to the concepts of cyclic and process times and combines elements from both. The discourse challenges linear time by giving emphasis to processes and embodiment in the here and now, on locally contextualised and individual interpretations and needs. Our past, present and future do not always appear to us causally or systematically following separate phases of life, but become entangled. Hours, days, months and years do not necessarily form a linear (progressive or regressive) continuum. Instead, we might rely on rhythmical and repetitive time, where we 'just' live our lives based on our bodily and social needs. Hence, according to the discourse of time of the mindful body, the future cannot be simply reduced to an object for rational planning.

Davies (1994) has studied the tensions between different time discourses in care work by using ethnographic data. Likewise, Fahlgren (2009) has examined the confrontation of discourses in 
social work practice. She uses her own experiences as a social worker in illustrating the interfaces between paradoxical discourses of time. In this research we aim to continue this line of research. We take time and its presence on professional client interaction as a research topic instead of treating it as 'neutral' background knowledge. It has been noticed that the topic of time is often missing totally or at least it has not been explored in depth or problematised sufficiently (Adam, 1990 and 1995; Davies, 1994; Levine, 2003). As in the previous research we shall analyse professionals' discourses of time, but will moreover make clients' time talk visible. This brings an extra dimension to the analysis: the possible clashes between professionals' and clients' uses of discourses of time. By studying how tensioned discourses are produced and negotiated in everyday, naturally occurring professional client encounters we strive to provide a new kind of context for studying discourses of time.

\section{DISCOURSES OF TIME AND IDENTITY CATEGORISATION IN PROFESSIONAL CLIENT INTERACTION}

Our research objective is to study how the discourse of linear time is produced, negotiated and possibly challenged by the discourse of the time of the mindful body in professional client interaction. Accordingly, we start from the assumption that culturally available discourses, in this case especially the discourse of linear time, are present in local conversations between professionals and clients (Gough, 1997). The discourses are understood as resources which participants use in interaction, not as external determinants. When analysing the participants' use

of time discourses, we also examine what kind of identity categories they simultaneously produce for themselves and for each other in the course of interaction. 
We draw on discursive psychology (Edwards and Potter, 1992; Wiggins and Potter, 2008) and membership categorisation analysis (Sacks, 1972a,b; Hester and Eglin, 1997; Housley and Fitzgerald, 2002) in the analysis. These research traditions provide analytical tools to examine how discourses of time are negotiated and used as resources in identity categorisation (Gough, 1997; Taylor and Wetherell, 1999). There is a long tradition of researching conversational remembering and memory talk in discursive psychology (e.g. Edwards et al., 1992; Middleton, 1997). However, in this text we focus especially on future oriented talk and on making sense of change. Although remembering and past events are inherent parts of future talk, their function in the rehabilitation planning context is to serve as a means in constructing potential futures for clients.

Following Benwell and Stokoe (2006: 6) we define identity categorisation in terms of who people are to each other, and how different kinds of identities are produced in spoken interaction and written texts'. The identities of professionals and clients are thus constantly produced and negotiated in social work (Juhila and Abrams, 2011). These parties form, what Sacks (1972a) calls as a standardised relational pair: the one part invokes the other. Psathas (1999) notices, that where two identity categories are paired together their rights and responsibilities are often reciprocal. There are cultural expectations about how the members of the categories should and can act in relation to each other.

Reciprocal identity categorisation is intertwined with rehabilitation planning talk between professionals and clients. Discussing and planning individual future pathways includes assessing clients' present identities and comparing them to the desirable ones. 'Accepting' this kind of assessment targeting and taking part in it are activities related to 'a good client' identity category 
(Juhila, 2003; Solberg, 2011). Accordingly, making assessments and creating future pathways for clients are activities associated with 'a good' professional identity category. So, the parties have certain rights and responsibilities in relation to each other. These kinds of reciprocal criteria of 'good' clienthood and professional work are bound to shared cultural knowledge about institutional helping work, which is produced, reworked and challenged in (inter)action. In this text we understand especially the discourse of linear time as cultural knowledge that is used as a resource in producing criteria for 'good' client and professional identity categories. Correspondingly, the discourse of the time of the mindful body challenges these criteria.

\section{SETTING, DATA AND ANALYSIS}

The institutional context of professional client conversations studied in this article is a supported housing unit run by a non-governmental organisation (NGO) in a large Finnish city. The unit is located on a conventional housing estate, where ordinary flats have been rented for the unit's clients. Some of the clients live in their own flats (not rented from the unit), but get equal support from the unit for their housing. A facility called 'support centre' located in the same area functions as a meeting point for the clients and the professionals. The five professionals employed in the activity are qualified social care and mental health workers. The unit produces professional mental health rehabilitation, the emphasis being on social rehabilitation. It is accountable for its work to municipalities as service purchasers, since it has a contract with them. The unit offers a community-based alternative to living in hospitals or nursing homes for people of working age who suffer from both mental health and substance abuse problems. It is not meant to be a permanent placement, but the principal aim of this intervention is to strengthen the clients' ability to lead normal and independent lives. After having spent a reasonable time in the unit the 
clients are expected to integrate into society as more self-responsible citizens. In other words, the unit serves as a half-way place on the clients' pathways from psychiatric hospitals and nursing homes to more independent living. The ideal pathways are seen as linear and progressive.

The professional tool in creating the future oriented ideal pathways is a rehabilitation plan. Making these plans is an inherent part of the unit's practices. In practice this processing is performed in a planning meeting where a client and his/her keyworker(s) are present. Plan making is established by law in Finland. The act concerning the client's position and rights in social welfare obliges professionals to make individual plans in collaboration with each of their clients whose clienthood is not regarded as only temporary. The law also directs professionals to assess the realisation of plans periodically. In the supported housing unit, plans are written by using a standardised form covering such topics as the state of health, medication, economic issues, general life situation, the aims of rehabilitation and the need of support and services in rehabilitation.

In this text our interest is not on plans as textual documents, but on client professional interaction in the planning meetings, whose institutional task is to produce and check the plans and assess their realisation. This institutional task is present in the interaction, but not in any straightforward way. We start from the assumption that the planning task produces time talk, which is based on the linear discourse of time. To put it more concretely, social rehabilitation aims at more independent living. Instead of seeing plans and planning as an abstract and rational phenomenon (planning model), we are interested in, by following Suchman's (1997: 50) advice, 'how people produce and find evidence for plans in the course of situated action', in this case in the course of conversations in professional client planning meetings. When investigating time talk in the 
planning meetings, we apply the theoretical and methodological approaches and concepts presented in the previous sections of this text and ask: 1) what time related words and expressions do participants use in interaction, 2) what kind of clients' future pathways do the participants create and anticipate, 3) how are the discourse of linear time and the discourse of the time of the mindful body present and used in interaction , 4) how is identity categorisation accomplished in regard to the future and to the different discourses of time (in regard to 'good' and 'bad' clienthood and professional work).

The data corpus consists of 13 audio-recorded planning meetings between the professionals and the clients. The data was gathered between 2008 -2010. The length of the meetings vary from 28 minutes to 63 minutes, the average length is 42 minutes. Nine of the clients are men and four women. The meeting talk was transcribed verbatim. The original language in the meetings was Finnish, but the excerpts have been translated into English for the purposes of this paper. The actual names of the clients have been changed to fictitious ones. All references to localities and services that might risk the anonymity of the persons involved have been removed. The permit for collecting data in the unit was applied for from the Board of Directors of the NGO. The clients, who participated in the study were expressly told that participation is voluntary and confidential, and that they can withdraw their consent at any stage. They were given written information about the person in charge and the contact persons in the research team and an overall description of the research. Each client completed a consent form before commencing data collection. The research complies with ethical principles of research in the humanities and social and behavioural sciences, as well as the Guidelines on Research Ethics by the Academy of Finland. 
The meetings follow loosely the structure of the standardised planning forms starting from personal information, current state of health and social well-being including possible problems or setbacks in them, and proceeding to the aims of rehabilitation and the means to achieve them. In spite of the form structure the content of conversations vary depending on each client's specific situation. Given that the institutional task of the meetings is to make rehabilitation plans, future talk is naturally strongly present in every conversation. The professionals generally promote step by step change in conversations. According to them, short-term and small-scale aims such as participation in the unit's social activities, cleaning one's flat weekly, learning to take care of one's own financial matters, eating healthily and taking exercise, lead gradually to a longer-term goal meaning living as independently as possible. They also stress that temporary setbacks do not matter if the main direction is right. All this follows the idea of the discourse of linear time.

In the majority of the meetings (10 of 13 meetings) the clients generally agreed with the professionals' agenda in the sense that they answered the questions about their current situations and joined in creating their rehabilitation aims and means. So, the participants of these meetings produced joint visions of the clients' short-term and long-term futures. Interestingly, in three meetings the participants' time talk clashed. In two of them clashing time talk continued throughout the whole meetings, and in one meeting joint and clashing time talk alternated. We interpret this clashing due to the clients' orientation to 'here and now' time, in other words the clients used the discourse of the time of the mindful body. We regard these exceptions important and worth analysing more closely, since they make visible the taken for granted discourse of linear time and show how important it is to hear alternative time talk even in such institutional settings which are devoted to planning and progress. In the following section we will first analyse how a joint vision of future is displayed in the data by presenting a typical example of the 
meetings with joint time talk. After that we will concentrate on those two exceptions, where clashing time talk was the dominant feature of the meeting interaction. The selected pieces of data have been chosen so that they illustrate best the spirit of the meeting in question. When analysing the extracts we follow the above stated four questions and demonstrate how time related words and expressions are present in the conversions (question 1), and how different kinds of client futures (question 2), the discourses of time (question 3) and related identity categorisations (question 4) are talked into being.

\section{JOINT FUTURE TALK}

The client of this planning meeting is in his middle thirties living alone but with children living elsewhere. He has been diagnosed to have an unspecified form of schizophrenia. He has suffered from a mixed substance abuse problem (alcohol and medicine) but has been a nonuser for about two years at the time of the planning meeting. The meeting, from which the following pieces of conversation are parts of, started with a positive atmosphere. The client told the worker that he was feeling fine at that moment. After that they discussed the client's health condition and his relations to his children. During the course of the conversation the client repeatedly raises one concern, namely his feelings of being unsafe and afraid in his own home. He lives alone, but supported by the unit. The next extracts deal with the client's mental disorder and his primary goals in rehabilitation. The first one is located in the first part of the conversation that lasted about 50 minutes and the second one in the later part.

C: The doctor at the psychiatric hospital for instance told me that I'd just have to adjust, that it's a disease I'll have to live with the rest of my life, like, schizophrenia. 
P: Yes, accepting it, that's like the first thing and I think you have gone a fair bit towards accepting it already and...

C: I have, yes.

P: ... worked a lot with...

C: Yes.

$P:$... that. And likewise, when you lead this peer group, the group for people who hear voices, it's like at the same time you also, you also care for yourself and work for yourself, don't you?

C: Yes.

P: Do you have some aims, matters that you'd still like to include in your rehabilitation plan?

C: Well perhaps my first priority aim is that I could make the home such....

P: The home, yes.

C: ... that I feel at home there.

P: That's it. And that is probably the most important...

C: Yes, yes, yes.

P. ... since everything else you manage pretty well.

Time is strongly present and negotiated in these extracts, as it is in the whole meeting and in the planning meetings in general (question 1). The participants use a lot of the future tense and conditional mood in their talk, which refers to matters anticipated to happen in the future: 'I'll have to live...', 'you'd still like', 'I could make...'. Future-oriented questions, like the professional's opening turn in the second extract, brings time up as a core topic of the meeting talk. However, this future talk is tied to the past and present, which together make narrative work in the course of conversation (Gubrium and Holstein, 2009: 39-121). The client's first turn in 
itself can be described as a short narrative. The doctor told something, which the client had to take seriously into account in his present and future life; schizophrenia is his permanent lifecompanion. Both the client and the professional support this narrative. The overall narrative present in the conversation is that the client is at a certain stage in his rehabilitation pathway. The professional emphasises already realised steps forward on this journey, such as moving toward accepting a mental disease, leading the peer group, working and caring for himself, and managing pretty well in everything except making his home feeling like a home. The client confirms these interpretations.

But what kind of future is eventually constructed for the client (question 2)? When looking at the first extract, the desirable future agreed by both parties of the conversation is, that the client will accept his disease, will learn to live with it, will take care of himself and will keep the disease under his control as much as he possibly can. In the second extract the professional asks the client to define his own future aims on the rehabilitation pathway. The client's answer produces again the control of disease as a desirable future or as a way to a desirable future, since he told earlier that hearing voices when staying alone at home prevents him from feeling that his flat is a real home. The professional confirms that the aim of making a flat a real home in the future is 'probably the most important' one.

We claim that the above described narrative about proceeding step-by-step along the rehabilitation pathway echoes the discourse of linear time (question 3). The participants of the conversation produce a progressive, ascendant pathway for the client. While there are still steps ahead to take, the direction is clearly upwards. What kind of the time related identity categorisations do the participants accomplish in the conversation (question 4)? Our main 
observation is that the identity categories displayed in the conversations are in alignment (Zimmerman, 1998). The client is categorised as being permanently mentally ill, but also as a rehabilitant who in the end, with the help of tailored rehabilitation, will learn to live with his disease (Pilgrim, 2008). Accordingly, the worker is categorised as an expert in professional rehabilitation work, whose responsibilities include supporting the client and helping him to plan his rehabilitation pathway. The alignment of these two categories and their reciprocality are displayed in the turns of conversation in many ways: the client tells about his state of condition and concerns, the professional supports the client, assesses his progress and encourages him to disclose his rehabilitation aims. All in all the participants in the conversation produce a joint vision of the future for the client.

\section{CLASHING TIME TALK: EXAMPLE 1}

Our first example of clashing time talk comes from the planning meeting of the single, 27 years old client who has a schizophrenia diagnosis and a history as a substance abuser. He has not got over his substance use, but suffers from relapses time to time. The meeting begins in a very different tone than the meeting analysed above. The professional starts by reading out the aims of the rehabilitation documented in the client's individual rehabilitation plan. The plan contains such aims as adapting a substance free way of life, accepting mental illness, participating in rehabilitative work and attending AA-group gatherings. The professional does not openly blame the client, but the client immediately responds by saying that he wants to comment on the realisation of these aims. He tells that the realisation has been unsuccessful. He confesses that he has not been able to increase his participation in the proposed activities. In addition, he has had a relapse along the way in recovering from his substance abuse problem, and he will therefore soon 
attend an intensive substance abuse treatment programme. The client accounts for these 'failures' being partly due to an unsuccessful change in his medication (Scott and Lyman, 1968). The following bits are from the various parts of the meeting that lasted 40 minutes. They illustrate well the tone of the whole conversation.

C: I'm the kind that gets going pretty slowly.

P: Yes, you need some time...

C: I do need a bit of time and...

$P:$... to internalise things.

C: ... I've had this wish for myself, that I've set for myself, that I could attend the AA groups even in the evening, I mean weekdays, because, I haven't managed to go. It's, the Sunday group has been the one that I've managed to attend.

C: But I can't set a definite day for it. See my own state of mind is such that I can't set a permanent, like I can't set myself a definite day except Sunday. It just depends so much on what my state of mind is, how I feel, as to whether I can attend a group or not.

P: It just crossed my mind, I can't remember who it was that said this, that you are able to go no matter what your feelings are, whatever it is, you could attend a group.

C: So you mean you could go.

C: See, I can cope with everyday things all right. But if it's decisions to do with the future or... P: You mean it's somehow difficult for you to think about that, to get a grip? 
C: It is, to get a grip on things, I do have this difficulty with thinking. In fact, what I can manage is to wake up in the morning and plan my day, the programme, and then try to get through it, so that's what it's like for me now, just a day at a time.

P: You mean it needs to be very concrete and a day at a time.

C: That I can manage.

P: So if it is too abstract you can't do it.

C: Making a weekly programme like, I just couldn't do it, I mean thinking ahead a whole week.

P: So it's good that you have these regular things in your week that you always do and decide to participate in, no matter how you feel, it's, that's precisely the rehearsing and learning.

Time related words and expressions are present in these extracts in many ways (question 1). The client's opening turn invokes time related discussion, when he characterises himself as 'the kind that gets going pretty slowly'. The professional confirms this characterisation and uses directly the concept of 'time' in his response. The response refers to the client's inner entity: he needs time. By repeating the professional's words, the client accepts this essential definition about himself. In the continuation of the conversation future time is connected to the aim of attending the AA group. The client visits the group regularly on Sundays, but according to his rehabilitation plan he should do it more often. When discussing the realisation of this aim and obstacles in reaching it, different time scales are present. The client talks about a one day perspective, and the professional about a one week perspective. Our interpretation is that different time scales create two kinds of future for the client (question 2). The client sees his future as based on day by day living. He plans each day and its programme only in the morning, the exception being the permanent Sunday event. The professional instead promotes the future with 
regular, weekly based plans. The client should have some things that he 'always' does. This idea of constant and regular repetition of certain activities makes the perspective of the future more far-reaching than the client's idea of day by day living. Hence, the participants disagree in their visions of the future.

How are the discourses of time present in the extracts (question 3)? It seems to us that the professional's version of the desired future represents the discourse of linear time. He encourages the client to see his future in the long run as based on well planned weekly schedules. Though the client is not 'ready' for that yet, he is able to reach this aim by persistently 'rehearsing and learning'. Hence, the professional's talk echoes progressive linearity: via persistent rehearsing and learning the future vision of the rehabilitation pathway can be seen as ascending. The client resists this positive vision, not the idea of regularity in itself. $\mathrm{He}$ 'hopes', that he could attend more often the AA group, but gives accounts of why this is not possible so far. He cannot promise to go, because everything depends on his 'state of mind', which forces him to live just in this moment or at a maximum on a one day scale. We argue that this client's reasoning clashes with the discourse of linear time and is based more on the logic of the discourse of the time of the mindful body (Fahlgren, 2009). The client does not promise to commit to the regular (taskoriented) week programme forming a linear progressive continuum, but states that he needs to live his life more according to his here and now emotional state.

What kind of identity categorisation are present in this conversation (question 4)? The client keeps to a self-categorisation that he is 'slow' and has unpredictable 'states of mind', which prevents him making long-term plans. The professional does not agree with this categorisation, but defines the client basically as an able person who can practice and learn to control his feelings 
and states of mind. This kind of encouraging is an activity which is clearly bound to the category of a rehabilitation worker (Sacks, 1972b). Accordingly, the activities bound to a rehabilitant's category are those such as learning and practicing, as well as accepting these activities. 'Failures' in these activities can be interpreted as signs of 'bad' clienthood.

\section{CLASHING TIME TALK: EXAMPLE 2}

In our second example of clashing time talk, two professionals and a client discuss the client's rehabilitation prospects. The client in question is a woman in her early twenties living alone. She has been diagnosed as having Asperger disorder, ADHD (attention deficit hyperactivity disorder) and a substance abuse dependency that is in an acute phase at the time of the meeting. The meeting is very short (18 minutes) and deals with one topic only. The professionals express their serious concern about the client's current situation. They make frightening prognoses about her future, if she does not change her behaviour and attitudes. The client repeats her own major concern during the whole course of the conversation, namely her fear of having cirrhosis of the liver. The first extract is from the very start of the conversation and the other one from the beginning of it. The content and the form of the conversation are very similar until the end of it.

P1: So the situation is this, Annu, that each and every application for education you've made has bounced back, and that's because of your continuous drinking, and the latest reply was from the rehabilitation centre, the psychologist in the education committee phoned to say that they won't accept your application because of your use of alcohol. In the same way, your application for trial work was rejected because of your drinking. And we've now come to a 
point where something must be done. I mean, you are no longer in control of things and your liver will soon go pop.

C: I actually meant to ask you, so with the hepatitis, I may get cirrhosis of the liver.

P1: Well you may get it faster than you normally would.

C: You mean I could already have it now?

P1: Well I couldn't say about that, but it's not going to help you at all here if you don't recognise that you have an alcohol problem.

((discussion about the situation and the possibility of the cirrhosis continues for a while))

P1: And we've got two options here, so you'd know, you'd understand what we're dealing with. We're dealing with a very serious and problematic disease, with alcoholism and what worries us here is that you're so very young, you've got your future ahead of you and that we should find a future career for you. And indeed, no school will accept you if you don't do something about the problem yourself. And you can't think, the way your friends say, that you'll be financed by the social services to the end of your life. You're stuck with institutions, you'll be in and out of the mental hospital the rest of your days. From the institution to community care, from community care to rehabilitation, institution, health centre, until you pop your clogs. This is the truth. What we need now is treat-

C: But what I've said to my friends, that the way I live, I tell them that this is just temporary.

P2: Yes, but the way you're going about it, it's going to be permanent.

P1: So what do you think, yourself, about this truth that we just slapped in your face?

C: I think it sounds pretty good. I'd just wanted to be sure that above all I don't have the cirrhosis yet, so I wouldn't have to be afraid of that. 
P1: Well, I don't think you have the cirrhosis yet, but it's, you're heading that way at an alarming rate unless you do something about it.

As the previous examples, this conversation is rich with time concepts and expressions (question 1). The first turn by the professional 1 forms a short narrative. He makes a summary of the client's near past, in which the 'continuous use of alcohol' is accounted for as being a cause (Bull and Shaw, 1992) for several failures and set-backs. He defines this moment as an inevitable turning-point: 'we've now come to a point where something must be done'. Time concepts are also used by both parties when discussing the possibility of cirrhosis: 'soon', 'faster', 'now'. Later on the professionals use concepts 'options', 'future' and 'permanent', and the client word 'temporary'.

When looking at what kinds of futures are constructed for the client (question 2), two versions are clearly stated in the professional 1's turn which he starts by saying 'and we've got two options here'. These two versions of the future are produced as extreme contrasts. On the one hand there is a descending, regressive vision: a marginal or even stigmatised career of life. And on the other hand an ascending, progressive vision: a 'normal' life career that starts by taking alcohol use into control (attending to treatment) and proceeds via education to work. However, the client does not define her own possible future as being this black and white. She does not recognise this moment as an ultimate turning-point, but says that what she has told to her friends is that her present way of living is only temporary. The professional 2 , however, challenges this interpretation. If the change does not start immediately, the current destructive way of living will become permanent. Another possible future that the client 'fears' and anticipates for herself, is the 'illness career'. This can be understood from her anxious questions about cirrhosis. 
When it comes to the discourses of time (question 3) we argue that the discourse of linear time is again clearly present in the professionals' talk. Unlike in the previous two planning meetings, the professionals' talk now contains two sub-discourses, namely a discourse of misery and a discourse of development (Fahlgren, 2009: 212-214). The future arrows show either down (misery) or up (development) from this very moment. However, as in our second case, our claim is that the client produces elements of the discourse of the time of mindful body in her talk. This is to be read from her talk, in which she continuously brings forward her acute concern about the possibility that she already has cirrhosis or that she might get it soon. This is her greatest concern and keeps her firmly in the moment. Hence, in this here and now situation she seems to be more in need of comforting or advisory discussion about her concern rather than a planning talk about her linear future. All in all, the client's and the professionals' talk are on different tracks, which according to our interpretation is due to the different and clashing time discourses. This creates a conversation in which the other party's agendas of talk are not 'heard' or responded to properly.

The participants accomplish various identity categorisations linked to the discourses of time in this conversation (question 4). The professionals' strong concern about the future of the client is accompanied by such client categorisations as 'young' and 'alcoholic'. The features bound to the category 'young' explain a lot: as a young person she should have a whole life ahead, she should educate herself, get a job and finally become a 'self-responsible' citizen. The category 'alcoholic' and the features bound to it contrast strongly with these expectations (Hester, 1998: 136-137). This conflict situation and the threat of a regressive future as a 'welfare dependent' citizen justifies the strong interventionist and disciplinary talk by the professionals in this planning 
meeting (Fahlgren, 2009). They act like 'good' rehabilitation professionals in this 'critical moment' of the client's life.

The client does not resist openly the professionals' disciplinary talk, but even says that what the professionals have said sounds 'pretty good'. However, given that she repeatedly presents the possibility of having cirrhosis as her main concern here and now, she does not align to the professionals' category expectations. In other words, she does not first of all define herself as a person at a crossroads needing to make an urgent choice between regressive and progressive directions. At this very moment she does not seem to seek disciplinary control or discussions about her long-term life plans. Instead she categorises herself as a possibly sick person who is in urgent need of health advice and of making sure she does not get cirrhosis. Her category expectations regarding the professionals' part are thus something else than what they actually display. At the last moment one of the professional partly responds to the client's concern, but uses the concern as a tool for promoting again the idea of this moment as an ultimate turningpoint: 'Well, I don't think you have the cirrhosis yet, but it's, you're heading that way at an alarming rate unless you do something about it'.

\section{CONCLUSION AND DISCUSSION}

In this paper we have analysed, with a small corpus of data, how words and expressions of time are constantly present and negotiated in the rehabilitation planning meetings among the clients and the professionals in the supported housing unit. When discussing the rehabilitation plans and assessing their realisation the participants simultaneously constructed possible futures for the clients. These futures got progressive, regressive or static tones depending on how the clients' 
situation, capabilities and behaviour were defined. The discourse of linear time dominated the interaction especially on the professionals' part. The clients' lives were assessed as pathways including ups and downs, but the preferable time arrows should be upwards. Static and regressive future predictions were defined as threats and failures in fulfilling the rehabilitation plans. In the first example the professional and the client shared this discourse. Their interaction flowed in mutual understanding and produced a joint vision of the future. However, in the last two cases the clients challenged the linear future orientation. They did not do it by overt resistance, but by describing their states of mind, needs or concerns here and now. This discourse of the time of mindful body embedded in certain moments did not fit in with the making of linear, long-term future plans proposed by the professionals. The result of this disalignment was that the clients either did not accept or did not respond to the professionals' future constructions. The client in the second example was against the professional's long-term plans and suggested living on a daily basis instead. In the third example the client's great fear about her health condition seemed to be her priority concern in the conversation, not the 'good' and 'bad' future predictions regarding her social rehabilitation made by the professionals.

The clients participating in the planning meetings suffered from both mental health and substance abuse problems at the time of the meetings. This raises the question of whether problems like this are somehow connected to the discourses of time. Do people suffering from them perhaps orient themselves more to the discourse of the time of mindful body, since they are not able to perceive their progressive futures or are too fragile to do so? This is not, however, a conclusion that can be made on the basis of our data, in which the linear discourse of time was dominant both in the talk of the professionals and the clients. Instead our claim is that the clients who interpreted their current situations as very unsettled and distressing, or who had immediate personal concerns, 
relied more easily on this alternative discourse of time. Their complex needs were the here and now, and processing them was not reducible to clear-cut procedures heading towards better futures. This seemed to be the case in our two examples of clashing time talk.

The dominance of the discourse of linear time in the planning meetings produced certain reciprocal identity categories for the participants. The professionals' responsibilities were to promote the preferable futures by advising and counselling on how to reach the aims of the rehabilitation plans. In the cases where reaching the aims were in real danger, their professional right was to make strong interventions in order to get the clients on the 'right' track again. Accordingly, the clients' responsibility was to participate in making their linear, progressive future plans, and in doing that they had a right to receive advice and counselling from the professionals. Success in fulfilling these responsibilities and rights produced 'good' clienthood and 'good' professional work. The participants aligned successfully with these reciprocal responsibilities and rights and thus created 'good' planning meetings in most of the meetings in our data corpus. But we also identified three 'vice versa' cases, where the clients 'failed' in fulfilling the expectations to participate in planning progressive pathways for themselves.

As we stated in the beginning of this paper, one received definition of rehabilitative social work is that it is change work and concentrates on creating ascending, positive futures for clients. Our aim in this article has not been to reject or downgrade this premise, since it certainly has many positive effects and consequences. Change work is based on clients' resources, which creates positive identity categories for them: they have strengths and capacities to solve their problems, and they are able to plan and change their lives. The discourse of misery, 'hopeless' future careers, are not supported. However, this resource oriented talk might also produce dysfunctional 
consequences. If clients themselves define their situation and capabilities as not being so hopeful they can end up resisting too optimistic visions. For instance, Caswell et al (2011) write how long-term unemployed people with multiple problems resisted labour market activation measures since they defined their prospects of really gaining employment as 'hopeless' under the prevailing labour market conditions. Likewise, the client in our second example repressed the professional's vision, which he defined as being too optimistic in regard to his own assessment about his mental capabilities. It seems to us, that in skillful professional work these kinds of clients' own 'misery' narratives are taken seriously, but at the same time such future visions are encouraged, where clients do not get stuck with the identities of incapability.

There is also a question related to professional practice that should be asked on the basis of this study. Is a progressive future, in the sense of an ascendant pathway, possible and relevant in every situation? Especially if progressing is defined in only one way, the 'failures' that interrupt movement to the preferred direction might create mission impossibles for both professionals and clients. 'Failures' force participants to account for the reasons why they took place. On these occasions, is the question of who is to blame a matter of importance? Blaming the clients would be the most unfortunate result. What makes this issue tricky and ethically difficult is that giving up the ascendant pathway might at the same time have positive consequences like relieving professionals and clients from the impossible and client-blaming missions, and negative consequences, such as producing stigmas and marginalized positions for the clients concerned in a society that believes strongly in progressive linear time and on ascending citizen.

To conclude, our research implicates that different discourses of time should be taken seriously in professional client interaction. When being simultaneously present in interaction, the discourse of 
linear time and the discourse of the time of mindful body might clash and produce disalignment. Our analysis of the last two examples illustrated how professionals held on to the linear time discourse at the same time as the clients brought forward their momentary concerns. If the professionals do not recognise the presence of the alternative time discourses, they will have difficulties in understanding the clients' rationales and needs. Hence, they easily end up interpreting the clients as 'difficult' and 'uncooperative', as 'bad' clients; and do not recognise the 'badness' of their own professional practice from the point of view of the discourse of the time of the mindful body.

Finally, we wish to emphasise that since we have used rather small-scale data in this study, it does not allow us to generalize the above conclusions and discussions to other social work settings, or even to settings conducting social rehabilitation work. However, the received idea of social work as change-oriented work indicates that the dominance of the discourse of linear time, the marginal position of the discourse of the time of mindful body and occasional clashes between these two discourses might be a fairly well-recognised phenomenon in other social work settings too. Our focus in this article has been on client professional interaction and the discourses of time accomplished in it, which is a rather under-researched domain so far. Hence, more research is needed in order to create further knowledge and evidence of the presence of the discourses of time in client professional interaction.

\section{References:}

Adam, B. (1990) Time and Social Theory. Oxford: Polity Press. 
Adam, B. (1995) Timewatch: The Social Analysis of Time. London: Polity Press.

Benwell, B. and Stokoe, E. ( 2006). Discourse and Identity. Edinburgh: Edinburgh University Press.

Bull, R. \& Shaw, I. (1992) 'Constructing Causal Accounting in Social Work', Sociology 26(4): 635-649.

Caswell, D., Eskelinen, L. and Olesen, S. P. (2001) 'Identity Work and Resistance Underneath the Canopy of Active Employment Policy', Qualitative Social Work. Published online before print November 28, 2011, doi: 10.1177/1473325011413629.

Coupland, N. and Nussbaum, J. F. (eds) (1993) Discourse and Lifespan Identity. London: Sage.

Davies, K. (1994) 'The Tensions between Process Time and Clock Time in Care-Work: The Example of Day Nurseries', Time \& Society 3(3): 277-303.

Dunmire, P. L. (2005) 'Preempting the Future: Rhetoric and Ideology of the Future in Political Discourse', Discourse \& Society 16(4): 481-513.

Edwards, D., Middleton, D. and Potter, J. (1992) Toward a Discursive Psychology of Remembering, The Psychologist 5: 56-60.

Edwards, Derek and Potter, Jonathan (1992). Discursive Psychology. London: Sage.

Fahlgren, Siv (2009) 'Discourse Analysis of Childcare Drama: Or the Interfaces between Paradoxical Discourses of Time in the Context of Social Work', Time \& Society 18(2/3): 208230.

Gough, B. (1997) 'Time as Ideological Dilemma: An Analysis of 'Ordinary' Discourse', Time \& Society 6(2/3): 213-236. 
Gubrium, J. F. and Holstein, J. A. (2009) Analyzing Narrative Reality. Los Angeles: Sage

Günther, K. and Raitakari, S. (2008) 'Documented Well-planned and Effective Client Process in Child Welfare', Nordisk Socialt Arbeid 248(3/4), 182-193.

Hall, C. (1997) Social Work as Narrative: Storytelling and Persuasion in Professional Texts. Aldershot: Ashgate.

Hepworth, D. H., Rooney, R. H., Dewberry R., G., Strom-Gottfried, K. and Larsen, J. (2009) Direct Social Work Practice: Theory and Skills. Eight edition. Belmont: Brooks/Cole.

Hester, S. (1998) 'Describing 'Deviance' in School: Recognizably Educational Psychological Problems', in C. Antaki and S. Widdicombe (eds) Identities in Talk, pp. 133-150. London: Sage Publications.

Hester, S. and Eglin, P. (1997) 'Membership Categorization Analysis: An Introduction', in S. Hester and P. Eglin (eds) Culture in Action: Studies in Membership Categorization Analysis, pp. 1-23, Lanham; MD: International Institute for Ethnomethodology and Conversation Analysis \& University Press of America.

Holstein, J. A. and Gubrium J. A. (2000) Constructing the Life Course. Second Edition. New York: General Hall, Inc.

Housley, W. and Fitzgerald, R. (2002) 'The Reconsidered Model of Membership Categorization Analysis', Qualitative Research 2(1): 59-83.

Juhila, K. (2003) 'Creating a 'Bad' Client: Disalignment of Institutional Identities in Social Work Interaction', in C.Hall, K. Juhila, N. Parton, and T. Pösö (eds) Constructing Clienthood in Social work and Human Services, pp 83-95, London: Jessica Kingsley Publishers. 
Juhila, K. and Abrams, L. (2011) 'Special Issue Editorial: Constructing Identities in Social Work Settings', Qualitative Social Work 10(3): 277-292

Leccardi, C. (1999) 'Time, Young People and the Future', Young 7(1): 3-18.

Levine, M. (2003) 'Times, Theories and Practices in Social Psychology', Theory \& Psychology 13(1): 53-72.

Middleton, D. (1997) 'The Social Organisation of Conversational Remembering: Experience as Individual and Collective Concerns', Mind, Culture and Activity 4(2): 71-85

Pilgrim, D. (2008) ‘Recovery’ and Current Mental Health Policy’, Chronic Illness 4: 295-304.

Psathas, G. (1999) 'Studying the Organization in Action: Membership Categorization and Interaction Analysis', Human Studies 22(2-4): 139-162.

Rojek, C., Collins, S. and Peacock, G. (1988) Social Work and Received Ideas. London: Routledge \& Kegan Paul.

Sacks, H. (1972a) 'An Initial Investigation of the Usability of Conversational Data for Doing Sociology', in David Sudnow (ed) Studies in Social Interaction, pp. 31-74. Glencoe: Free Press.

Sacks, H. (1972b) 'On the Analysability of Stories by Children', reprinted in J. Coulter (ed) (1990) Ethnomethodological Sociology, pp. 254-270. Aldershot: Edward Elgar Publishing Company.

Sacks, H. (1992) Lectures on Conversation, volumes 1 (LC1) and 2 (LC2). Edited by Gail Jefferson. Oxford: Basil Blackwell.

Scott, M. B. and Lyman, S. M. (1968) 'Accounts', American Sociological Review 33(1): 46-62. 
Solberg, J. (forthcoming) 'Activation Encounters: Dilemmas of Accountability in Constructing Clients as 'Knowledgeable', Qualitative Social Work.

Solberg, J. (2011) 'Activation Encounters: Dilemmas of Accountability in Constructing Clients as 'Knowledgeable'”, Qualitative Social Work 10(3), 381-398.

Suchman, L. A. (1987) Plans and Situated Actions: The Problem of Human Machine Communication. Cambridge: Cambridge University Press.

Taylor, S. and Wetherell, M. (1999) 'A Suitable Time and Place: Speakers' Use of 'Time' to do Discursive Work in Narratives of Nation and Personal Life', Time \& Society 8(1): 39-58.

Wiggins, S. and Potter, J. (2008) 'Discursive Psychology', in C. Willig, C. and W. Hollway (eds) Handbook of Qualitative Research in Psychology, pp. 72-89. London: Sage.

Zimmerman, D. H. (1998) 'Identity, Context and Interaction', in C. Antaki and S. Widdicombe (eds) Identities in Talk, pp. 87-106, London: Sage. 